\title{
Pengembangan Potensi Destinasi Wisata Curug Angkrek melalui Media Sosial di Kp. Cimuncang, Desa Karangnunggal, Kabupaten Tasikmalaya Jawa Barat
}

\author{
Aris Ariyanto $^{1 *}$, Agus Sudarsono ${ }^{2}$, Ivantan $^{3}$, Mada Faisal Akbar ${ }^{4}$, Munarsih $^{5}$ \\ 1,2,3,4,5 Program Studi Manajemen, Fakultas Ekonomi, Universitas Pamulang \\ Jl. Surya Kencana No.1, Pamulang Barat, Kec. Pamulang \\ Kota Tangerang Selatan, Banten 15417 \\ *Penulis Korespodensi: dosen02492@unpam.ac.id
}

\begin{abstract}
ABSTRAK
Kegiatan ini bertujuan untuk memotivasi dan memberikan penyuluhan masyarakat dalam mengelola dan memikirkan tata kelola yang efektif guna mengembangkan potensi wisata di desa Karangnunggal Kecamatan Karangnunggal Kabupaten Tasikmalaya. Metode yang dipakai yaitu dengan berbagai metode ceramah, diskusi dan tanya jawab, serta pendampingan bagi masyarakat melalui pelatihan Hasil dari kegiatan ini adalah masyarakat dan pemuda karang tarurna kampung Cimuncang Desa Karangnunggal mampu mempromosikan destinasi Curug Angkrek lewat sosial media dengan baik sehingga dapat mewujudkan destinasi Curug Angkrek sebagai tempat wisata pilihan masyarakat sekitar maupun masyarakat luas sehingga bisa menjadi sumber ekonomi baru baik bagi pemerintah desa maupun bagi masyarakat kampung Cimuncang.

Kata Kunci: Pengembangan Destinassi Wisata, Curug Angkrek, Media Sosial.
\end{abstract}

\begin{abstract}
This activity aims to motivate and provide public education in managing and thinking about effective governance to develop tourism potential in the Karangnunggal village, Karangnunggal sub-district, Tasikmalaya regency. The method used is a variety of methods of lectures, discussions and questions and answers, as well as assistance to the community through training. The results of this activity are the community and youth of Tarurna Karang village Cimuncang Karangnunggal village capable of promoting the Currek Angkrek destinations through social media so well that it can realize the destinations of the Curug Angkrek as a tourist choice of the surrounding community and the wider community so that it can become a new economic source for both the village government and the Cimuncang community.

Keywords: Tourism Tourism Development, Angkrek Waterfall, Social Media.
\end{abstract}

\section{PENDAHULUAN}

Pengembangan tempat wisata dapat membawa banyak manfaat dan keuntungan (Laras \& Gunawijaya, 2016). Pembangunan atau pengembangan kepariwisataan 
Aris Ariyanto, dkk

diarahkan supaya menjadi sektor andalan yang mampu membantu atau bahkan menyaingi kegiatan bidang ekonomi maupun kegiatan sektor-sektor lain yang terkait (Sutiarso, 2017). Upaya pengembangan dan pendayagunaan berbagai potensi kepariwistaan nasional, bertujuan untuk meningkatkan lapangan kerja, pendapatan masyarakat, pendapatan daerah dan pendapatan negara serta penerimaan devisa (Luthfi, 2013). Mengingat luasnya kegiatan yang harus dilakukan untuk mengembangkan kepariwisataan, maka perlu dukungan dan peran serta yang aktif dari masyarakat(Syarifuddin, 2018) .

Usaha mengembangkan suatu daerah tujuan wisata harus memperhatikan berbagai faktor yang berpengaruh terhadap keberadaan suatu daerah tujuan wisata. Salah satu faktor yang harus diperhatikan adalah pemberian informasi ke masyarakat luas (Ari Waluyo, S.ST, M.M, 2018). Minimnya informasi ini membuat banyak masyarakat mencari informasi mengenai tempat wisata melalui brosur, komunitas, promosi, buku, dan terutama adalah melalui internet. Kebanyakan wisatawan dalam dan luar negeri mencari informasi mengenai tempat wisata di Indonesia melalui internet.

Dengan semakin berkembangnya internet di Indonesia juga berdampak positif bagi pariwisata Indonesia. Biaya promosi untuk tempat tujuan wisata semakin murah dengan internet (Rusdi, 2019). Masyarakat dalam negeri dan luar negeri dapat mengakses informasi tentang tempat wisata yang ingin mereka tuju. Namun, di Indonesia informasi tempat wisata masih terbatas hanya pada tempat tujuan wisata yang sudah terkenal. Bagaimana nasib tempat pariwisata lainnya di Indonesia yang tidak kalah bagusnya dari tempat wisata yang sudah ada? Kesulitan masyarakat dalam mengakses informasi mengenai tempat wisata berkutat pada hal yang sama seperti, bagaimana biaya transportasi, makan, budaya, tempat tinggal, objek wisata, dan masih banyak hal lainnya yang belum banyak dijelaskan. Untuk mencari informasi mengenai hal-hal yang telah disebutkan di atas tidak jarang wisatawan menghabiskan banyak waktu mereka selama berjam-jam untuk mencari informasi tersebut di internet dan banyak dari mereka tidak mendapat jawaban yang memuaskan.

Salah tempat wisata yang dimiliki oleh Desa Karangnunggal, yang memiliki potensi destinasi wisata yang sangat bagus untuk di kembangkan yaitu air terjun yang dinamai penduduk setempat dengan nama "Curug Angkrek". Curug Angkrek itu sendiri memang belum menjadi daya tarik wisata lokal maupun nasional dikarenakan kurang menyebarnya informasi atau promosi, belum ada sarana dan prasarana yang menunjang sebagai bahan untuk meng explore tempat wisata tersebut seperti, media online maupun offline.

\section{METODE PELAKSANAAN}

Metode Berikut beberapa metode pelatihan yang biasa digunakan pada saat proses pelatihan berlangsung:

1. Metode Ceramah, Metode ceramah merupakan metode yang sampai saat ini sering digunakan oleh setiap pelatih.

2. Metode Demontrasi merupakan salah satu metode yang cukup efektif dalam proses pelatihan, karena dapat membantu siswa untuk mencari jawaban dengan usaha sendiri berdasarkan fakta atau data yang benar. 
3. Dokumentasi adalah suatu metode untuk mencari data variabel yang berupa catatan-catatan penting, transkrip nilai, buku, prasasti dan sebagainya (Suharsimi Arikunto 2010:130).

Dalam pelatihan ini, nara sumber berfokus kepada masyarakat Kp. Cimuncang, Desa Karangnunggal, Kecamatan Karangnunggal, Kabupaten Tasikmalaya, Jawa Barat. .Dimana strategi ini dipilih karena era saat ini adalah era New Media, dimana media sosial adalah cara yang murah dan effectif dalam melakukan penyebaran informasi.

\section{HASIL DAN PEMBAHASAN}

Penggunaan teknologi digital berupa media sosial telah memengaruhi semua aspek termasuk aspek promosi tempak wisata yang memang sedang digalakkan oleh pemerintah setempat, tentu tidak terlepas dukungan warga masyarakat sekitar khususnya anggota karang tarunayang memang masih relatif berusia muda. Penggunaan media sosial diharapkan dapat digunakan sebagai salah satu pembuka cakrawala agar Curug Angkrek semakin dikenal oleh dunia luas. Jika curug Angkrek tersebut semakin banyak menarik para wisatawan, secara otomatis bisa membuka peluang usaha usaha baru juga seperti usaha warung, usaha penyewaan tempat istirahat, usaha jasa guide, jasa parkir dan masih banyak lagi usaha usaha lain yang nantinya akan membagun perekonomian desa,khususnya warga di sekitar tempat wisata tersebut.

Dengan adanya media sosial memungkinkan banyak calon wisatawan memperoleh seluruh informasi mengenai Curug Angkrek melalui internet, dan memungkinkan para wisatawan untuk selalu memantau dan mengikuti media sosial atau akun-akun Curug Angkrek, baik akun Instagram, Youtue, Facebook, Twiteer, Line atau akun-akun yang lain yang dikelola.

Model promosi melalu media sosial sesuai dengan perkembangan teknologi komunikasi dan informasi saat ini. Dengan diadakan pelatihan promosi melalu media sosial peserta penyuluahn nantinya dituntut lebih aktif dalam dalam mengelola akunakun media sosialnya agar Curug Angkrek semakin terkenal dan menjadi destinasi pariwisata yang maju.

Diera digital promosi pariwisata memang tidak cukup hanya dilakukan melalui media tradisional ataupun konvensional. Media konvensional adalah media yang berbayar, misalkan iklan luar ruang, seperti baliho, billboard, brosur, leaflet, iklan di media cetak, radio, dan juga televisi. Media-media tersebut dinilai berbiaya tinggi, tidak interaktif, kurang dapat diperbaharui setiap saat, dan sulit diprediksi efektivitasnya. Selain itu, tidak dapat diketahui secara langsung respons, minat, dan motif kunjungan wisatawan ke suatu tempat wisata.

Promosi yang biasanya hanya menggunakan media tradisioanl yaitu melalui mulut ke mulut, poster atau pamplet, kini berubah menjadi promosi melalui media sosial yang bias dilakukan dimana saja kapan saja dan siapa saja, entah itu di rumah di sekolah di tempat kerja atau bahkan di tempat-tempat privasi sekalipun, dan bias dilakukan oleh tua , muda, perangkat desa, warga maupun wisatawan yang pernah berkunjung ketempat Curug Angkrek tersebut.

Perubahan metode promosi akan semakin berkempang pesat, jika media sosial tersebut dikeloa dengan baik, serta menggunakan trik atau cara cara jitu agar promosi tepat sasaran yaitu menyembar dengan cepat dan tepat. Segmen yang tepat tentu tidak 
Aris Ariyanto, dkk

akan membuat sia-sia promosi menggunakan media sosial. Selain sasaran yang tepat waktu berpromosi juga hal yang mempengaruhi promosi tersebut berjalan maksimal atau tidak.

\section{PENUTUP}

Hasil kegiatan PkM di kampung Cimuncang Desa Karangnunggal melalui aplikasi Zoom berjalan dengan lancar. Perserta terlihat antusias mengikuti pemyuluhan walau keterbatasan sarana prasana. Pelatihan penggunaan sosial media memberikan kemudahan masyarakat dalam melakukan kegiatan berpromosi dalam pengembangan pariwisata Curug Angkrek agar lebih dikenal masyarakat luas sehingga dapat menumpuhkan pertumbuhan baik disektor pariwisata maupun sektor perekonomian desa Karanggnunggal khususnya kampung Cimuncang.

Berikut adalah beberapa saran untuk pemerintah setempat maupun masyarakat dalam meningkatkan potensi destinasi Pariwisata Curug Angkrek di Kampung Cimuncang Desa Karangnunggal, Kabupaten Tasikmalaya.

1. Membuat akun media sosial sebagai media terpisah dari akun pribadi.

2. Post foto-foto menarik Curug Angkrek secara berkala dan rutin,

3. Usahakan setiap posting foto dan kegiatan yang berkaitan dengan Curug Angkrek memberikan tanda pagar (hashtag) sebagai katakunci dan tag ke akun akun yang mempunyai banyak follower.

4. Menjawab segala pertanyaan dari follower untuk menandakan bahwa akun aktif.

\section{DAFTAR PUSTAKA}

Alma, (2013), Manajemen Pemasaran Dan Pemasaran Jasa, CV Alfabeta, Bandung.

Arikunto, Suharsimi (2010), Prosedur Penelitian: Suatu Pendekatan Praktis. Edisi Revisi, Rineka Cipta. Jakarta.

Ariyanto, Aris (2019), The Influence of Price and Service Quality on Customer Satisfaction at PT Sarana Estate

Ari Waluyo, S.ST, M.M, S. B. S. (2018). Perancangan Sistem Informasi Geografis Pariwisata Berbasis Web Di Dinas Kepemudaan Dan Olahraga Dan Pariwisata Kabupaten Kebumen. Jurnal E-Komtek.

Laras, A. P., \& Gunawijaya, J. (2016). Wisata Halal Di Antara Keuntungan Ekonomi dan Politis. Journal of Indonesian Tourism and Policy Studies.

Legawa, Aby. (2008). Komponen Produk Pariwisata dengan Acuan Khusus. Jakarta: Gramedia Pustaka

Luthfi, M. (2013). Pengembangan Pariwisata Dan Dampak Sosial Ekonomi Di Bandar Lampung. Jurnal Riset Akuntansi Dan Manjemen.

Rusdi, J. F. (2019). Peran Teknologi pada Pariwisata Indonesia. Jurnal Accounting Information System (AIMS). https://doi.org/10.32627/aims.v2i2.78

Sutiarso, M. A. (2017). Pengembangan Pariwisata Yang Berkelanjutan Melalui Ekowisata. Manajemen Kepariwisataan Di Sekolah Tinggi Pariwisata Bali Internasional (STPBI).

Stelzner, MA (2012). Social Media Marketing Industry Report. How Marketers Are Using Social Media to Grow Their Business 
Stockdale, Ahmed, \& Scheepers. (2012). Identifying Business Value from The Use of Social Media: An SME Perspective. Pacific Asia Conference on Information Systems. Association for Inforamtion System Electronic Library

Sedarmayanti, (2001). Sumber Daya Manusia dan Produktivitas Kerja. Jakarta : Mandar Maju

Syarifuddin, S. (2018). The Implementation of Community Based Tourism Concept In the Management of Natural Tourism in Kampoeng Karts Rammang-Rammang Maros Regency. UNM Geographic Journal.

https://doi.org/10.26858/ugj.v2i1.7232 